Acta Crystallographica Section F

Structural Biology

and Crystallization

Communications

ISSN 1744-3091

R. J. Hussey, ${ }^{a}$ L. Coates,

R. S. Gill, ' J. N. Wright, ${ }^{a}$

M. Sarwar, ${ }^{\text {a }}$ S. Coker,

P. T. Erskine, ${ }^{\text {c }}$ J. B. Cooper, ${ }^{\mathrm{C} *}$

S. Wood, ${ }^{\text {I. N. N Clarke, }}{ }^{d}$

P. R. Lambden, ${ }^{d}$ R. Broadbridge

and P. M. Shoolingin-Jordan ${ }^{a}$

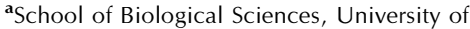
Southampton, Southampton SO16 7PX, England, ${ }^{\mathbf{b}}$ Oak Ridge National Laboratory, Oak Ridge, TN 37831, USA, 'Laboratory of Protein Crystallography, Centre for Amyloidosis and Acute Phase Proteins, UCL Department of Medicine (Royal Free Campus), Rowland Hill Street, London NW3 2PF, England, 'Molecular Microbiology Group, Division of Infection, Inflammation and Immunity, University Medical School, Southampton General Hospital, Southampton SO16 6YD, England, and ${ }^{\mathbf{e}}$ Peptide Protein Research Ltd, E2 Knowle Village Business Park, Wickham, Hants PO17 5DY, England

Correspondence e-mail: jbcooper@medsch.ucl.ac.uk

Received 17 June 2010

Accepted 29 September 2010

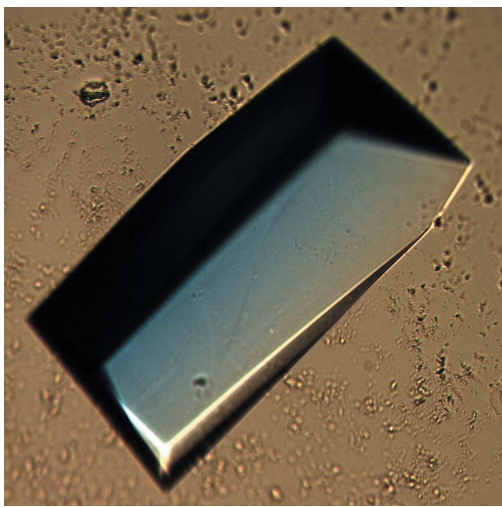

\section{Crystallization and preliminary X-ray diffraction analysis of the protease from Southampton norovirus complexed with a Michael acceptor inhibitor}

Noroviruses are the predominant cause of human epidemic nonbacterial gastroenteritis. Viral replication requires a cysteine protease that cleaves a $200 \mathrm{kDa}$ viral polyprotein into its constituent functional parts. Here, the crystallization of the recombinant protease from the Southampton norovirus is described. Whilst the native crystals were found to diffract only to medium resolution $(2.9 \AA)$, cocrystals of an inhibitor complex diffracted X-rays to $1.7 \AA$ resolution. The polypeptide inhibitor (Ac-EFQLQ-propenyl ethyl ester) possesses an amino-acid sequence designed to match the substrate specificity of the enzyme, but was synthesized with a reactive Michael acceptor group at the C-terminal end.

\section{Introduction}

Noroviruses are the most common cause of acute viral gastroenteritis in humans, with epidemics commonly occurring in hospitals and on ocean liners (Clarke \& Lambden, 2005). The virus, which is transmitted through contaminated food and water, can infect and replicate in enterocytes of the epithelial cell lining of the small and large intestine (Green, 2007). Currently, there is neither vaccine nor antiviral therapy available.

The norovirus genome consists of a molecule of single-stranded positive-sense RNA $(7.7 \mathrm{~kb})$ comprising three open reading frames ORF 1, ORF 2 and ORF 3 (Lambden et al., 1993, 1995). ORF 1, which is located at the $5^{\prime}$-terminus of the genome, encodes a large nonstructural $200 \mathrm{kDa}$ polyprotein. ORF 2 encodes the major capsid protein VP1 and ORF 3 codes for a small basic protein VP2 that is thought to assist in the viral assembly process (Bertolotti-Ciarlet et al., 2003). In vitro translation and mutagenesis studies indicated that the $200 \mathrm{kDa}$ ORF 1 polyprotein is cleaved by the action of the viral protease to generate initially three separate functional protein products (Liu et al., 1996). Full processing of the precursor polyprotein generates an N-terminal protein (p48), an NTPase (p41), a 3A-like protein (p22), a Vpg protein (p16), a 3C-like protease (p19) and an RNA polymerase (p57) (Liu et al., 1999). The protease also inhibits cellular translation by cleavage of the poly(A)-binding protein, thereby allowing preferential viral protein expression compared with host proteins (Kuyumcu-Martinez et al., 2004). Since processing of the $200 \mathrm{kDa}$ precursor polyprotein is essential to yield functional viral proteins, the viral protease presents itself as an attractive target for antiviral strategies.

Enzymes in this family are cysteine proteases that display a trypsinlike or chymotrypsin-like serine protease fold, a property which distinguishes them from other viral proteases (Matthews et al., 1994). The Southampton norovirus protease has a preference for cleavage at LQ-GP and LQ-GK sequences, but it can also cleave at ME-GK, FE-AP and LE-GG (where '-' indicates the scissile bond). In the nomenclature of Schechter \& Berger (1967), the substrate residues each side of the scissile bond are labelled $\mathrm{P} 1$ and $\mathrm{P}^{\prime}$ and the remainder are labelled according to the scheme ...P3, P2, P1, P1', $\mathrm{P} 2^{\prime}, \mathrm{P}^{\prime} \ldots$ The corresponding subsites in the enzyme are labelled S3, S2 etc. It appears that the Southampton norovirus protease 
preferentially accommodates a glutamine or glutamate residue at the $\mathrm{P} 1$ position, a small amino acid at $\mathrm{P}^{\prime}$ and a hydrophobic residue at $\mathrm{P} 2$. Modified peptide inhibitors that include the preferred amino-acid recognition sequence but possess a C-terminal moiety capable of reacting with the active-site cysteine residue have been developed for other viral cysteine proteases and in vitro studies have shown that these completely inhibit the catalytic activity and have antiviral properties in vivo (Dragovich et al., 1998a,b, 2003). One such modified peptide inhibitor includes a Michael acceptor group at its C-terminus, which undergoes nucleophilic attack by the active-site thiol, resulting in the inhibitor becoming irreversibly bound to the enzyme (Fig. 1; Dragovich et al., 1998a).

A number of noroviral proteases have been analysed by X-ray diffraction, e.g. those from the Chiba and Norwalk viruses (Nakamura et al., 2005; Zeitler et al., 2006). In this paper, we describe the crystallization of the Southampton norovirus protease, initially in a form that diffracted to medium resolution. A marked improvement in crystal quality was achieved by cocrystallization of the enzyme with the Michael acceptor peptide inhibitor (MAPI) acetyl-Glu-Phe-GlnLeu-Gln- $X$, in which a peptide mimicking part of the natural substrate consensus sequence is coupled to a propenyl ethyl ester moiety $(X)$ in order to modify the active-site cysteine. The resulting cocrystals belonged to space group $P 2_{1} 2_{1} 2_{1}$ and diffracted synchrotron radiation to $1.7 \AA$ resolution.

\section{Protein expression and purification}

The protease from Southampton virus was expressed in Escherichia coli BL21 (DE3) pLysS transformed with a plasmid pSV3C derived from pT7-7 (USB Corp.) harbouring DNA for the protease gene flanked by $N d e \mathrm{I}$ and BamHI restriction sites that were introduced during amplification of the gene using standard PCR methods. Cells transformed with the plasmid were grown in Luria-Bertani medium with $50 \mu \mathrm{g} \mathrm{ml}^{-1}$ ampicillin in shaken flasks at $310 \mathrm{~K}$ and induced using isopropyl $\beta$-D-1-thiogalactopyranoside (IPTG), which was added to a final concentration of $1 \mathrm{~m} M$ for the last $3 \mathrm{~h}$ of bacterial cell growth. The harvested cells were sonicated and the supernatant was applied onto a column of SP Sepharose cation-exchange matrix (GE Healthcare) in phosphate buffer $\mathrm{pH} 7.65$ containing $5 \mathrm{mM}$ $\beta$-mercaptoethanol, followed by elution with a gradient to $1 \mathrm{M} \mathrm{NaCl}$. After desalting with a Sephadex G25 column, the enzyme was applied onto a Source $15 \mathrm{~S}$ column (GE Healthcare) in the same buffer, followed by elution with a gradient to $1 M \mathrm{NaCl}$. After a final desalting step with Sephadex G25, the protein was obtained with a yield of approximately $20 \mathrm{mg}$ per litre of culture and was concen-
Table 1

Kinetic data for the hydrolysis of pNA substrates by the Southampton virus protease.

The smallest substrate Ac-QLQ-pNA was not detectably cleaved and therefore no parameters could be determined.

\begin{tabular}{llll}
\hline Substrate & $K_{\mathrm{M}}(M)$ & $k_{\text {cat }}\left(\mathrm{s}^{-1}\right)$ & $k_{\text {cat }} / K_{\mathrm{M}}\left(M^{-1} \mathrm{~s}^{-1}\right)$ \\
\hline Ac-QLQ-pNA & - & - & - \\
Ac-FQLQ-pNA & $1.5 \times 10^{-3}$ & 0.08 & 55 \\
Ac-EFQLQ-pNA & $3 \times 10^{-4}$ & 0.14 & 463 \\
Ac-DEFQLQ-pNA & $8 \times 10^{-4}$ & 0.33 & 416 \\
\hline
\end{tabular}

trated to $10 \mathrm{mg} \mathrm{ml}^{-1}$ and stored in $50 \%$ glycerol. The molecular weight of the purified enzyme was determined by electrospray mass-spectrometry as 19258 , which is consistent with the predicted amino-acid sequence of 181 residues and confirms that the protease has self-excised from the flanking sequences encoded by the expression construct.

\section{Chromogenic substrate synthesis, kinetic assay and inhibitor synthesis}

For kinetic studies of the protease specificity, a series of peptides were synthesized that provided a convenient spectrophotometric assay of its proteolytic activity. The chromogenic peptides Ac-QLQ-pNA, Ac-FQLQ-pNA, Ac-EFQLQ-pNA and Ac-DEFQLQ-pNA were synthesized using a combination of standard Fmoc solid-phase chemistry and synthetic techniques (Merrifield, 2007). Each peptide mimics residues of the protease-recognition sequence within the $200 \mathrm{kDa}$ ORF 1 polyprotein which experiences the greatest rate of cleavage (DEFQLQ-GKMYDF; Liu et al., 1999). All peptides were synthesized with an acetylated $\mathrm{N}$-terminus and a C-terminus linked to a para-nitroaniline group (Whitmore et al., 1995; Kaspari et al., 1996). MALDI-Q-TOF-MS was used to confirm correct synthesis following reverse-phase purification of each product in DMSO. In the assay, cleavage of the C-terminal para-nitroanilide (pNA) group yields free para-nitroaniline, which can be followed spectrophotometrically at $405 \mathrm{~nm}$. The C-terminal chromogenic glutamine-pNA is a complicating factor during peptide-chain extension since the C-terminal residue of the peptide would normally be attached to the support resin via its main-chain carboxyl. In this instance, pNA has to be attached at the glutamine carboxyl and therefore this residue must be linked to the support resin by its side chain. Hence, the pNA derivative of glutamate, rather than glutamine, was synthesized first using Fmoc-L-Glu $(\gamma \mathrm{OtBu}) \mathrm{OH}$, in which the side-chain carboxyl is protected with a tertiary butyl ester group. The glutamate side chain<smiles>CCOC(=O)/C=C/C(CCC(N)=O)NC(=O)C(CC(C)C)NC(=O)C(CCC(N)=O)NC(=O)C(Cc1ccccc1)NC(=O)C(CCC(=O)O)NC(C)=O</smiles>

Figure 1

Structure of the Michael acceptor peptide inhibitor (MAPI) designed for the Southampton virus protease. 
of the Fmoc-L-Glu $(\gamma \mathrm{OtBu})$-pNA product was then selectively deprotected (with $95 \%$ trifluoroacetic acid) and linked to a Rink amide MBHA resin (Rink, 1987) using a standard procedure for the synthesis of peptide amides. Following completion of the remaining synthesis and deprotection cycles, cleavage of the desired peptide from the resin (with $95 \%$ trifluoroacetic acid) results in amination of the carboxyl linking group, which in this case yielded a glutamine residue at the C-terminus of the peptide-pNA.

The rate of cleavage of each pNA substrate by the protease was monitored using a Nanodrop ND1000 spectrophotometer. The assay involved dissolving the substrates in DMSO and diluting them into a solution containing $100 \mathrm{~m} M$ Tris $\mathrm{pH} 8.5$ and $5 \mathrm{~m} M \beta$-mercaptoethanol to give final substrate concentrations in the $0.1-3.0 \mathrm{~m} M$ range and a final enzyme concentration of $0.1 \mathrm{mg} \mathrm{ml}^{-1}$. The absorbance at $405 \mathrm{~nm}$ of $2 \mu \mathrm{l}$ samples taken from the reaction mixture was measured at $1 \mathrm{~min}$ intervals over a $10 \mathrm{~min}$ period. The initial rates of cleavage of the chromogenic pNA peptides established that AcEFQLQ-pNA was the best substrate in terms of specificity constant $\left(k_{\text {cat }} / K_{\mathrm{M}}\right.$ ratio; see Table 1$)$.

Subsequently, a polypeptide inhibitor (MAPI) with the same sequence as the optimal substrate and a Michael acceptor group at the C-terminus was synthesized, essentially by the methods described in Dragovich et al. (1998a), and purified by reverse-phase chromatography. The inhibitor (shown in Fig. 1) has the sequence Ac-EFQLQ- $X$, where $X$ is the propenyl ethyl ester extension (the Michael acceptor) which undergoes nucleophilic attack by the activesite thiol. This generates a stable covalent complex between the enzyme and the inhibitor linked by a thioether bond (Govardhan \& Abeles, 1996). For synthetic convenience, the peptide region of the inhibitor mimics only the nonprime residues of the bound substrate, i.e. P5-P1. The success of each step in the synthesis and the purity of the final compound was confirmed by MALDI-Q-TOF-MS. Since this inhibitor was found to inactivate the enzyme irreversibly and rapidly ( $<1 \mathrm{~min}$ ), no further compounds were synthesized for the crystallographic work.

\section{Crystallization and preliminary X-ray analysis}

For all crystallization studies, samples of protease that were stored in glycerol were exchanged using a Sephadex G25 mini-column into $10 \mathrm{~m} M$ phosphate buffer $\mathrm{pH} 7.45$ containing $5 \mathrm{~m} M \beta$-mercapto-

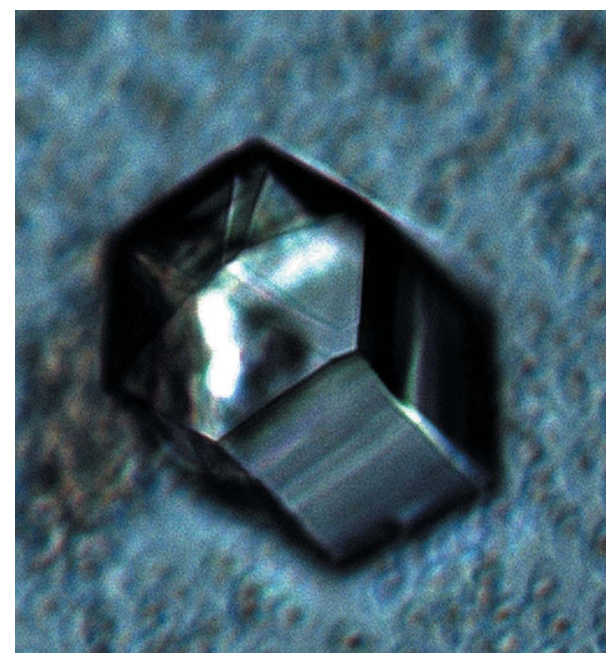

Figure 2

A crystal of native Southampton virus protease. ethanol and then concentrated to $3 \mathrm{mg} \mathrm{ml}^{-1}$. Crystals of the native enzyme were obtained by the vapour-diffusion method in several conditions at room temperature using the Jena Biosciences JBScreen Classic screens; following further screening the optimum conditions were found to be 7\% PEG 8000, $0.1 M$ HEPES $\mathrm{pH} 7.5$ with $8 \%(v / v)$ ethylene glycol (Fig. 2). Crystals were frozen by transferring them

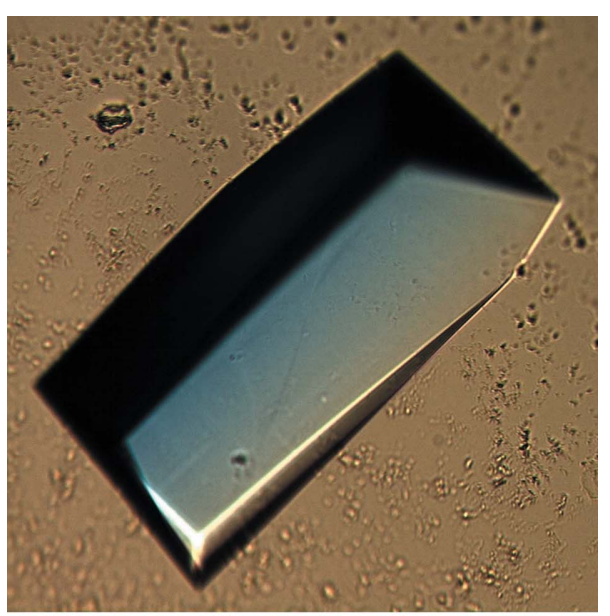

(a)

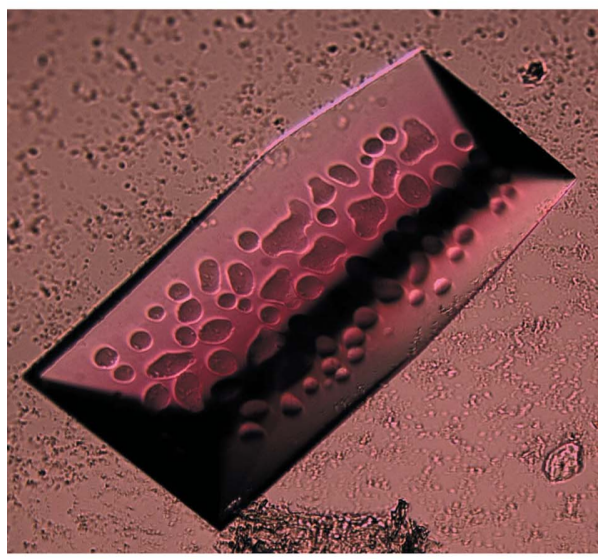

(b)

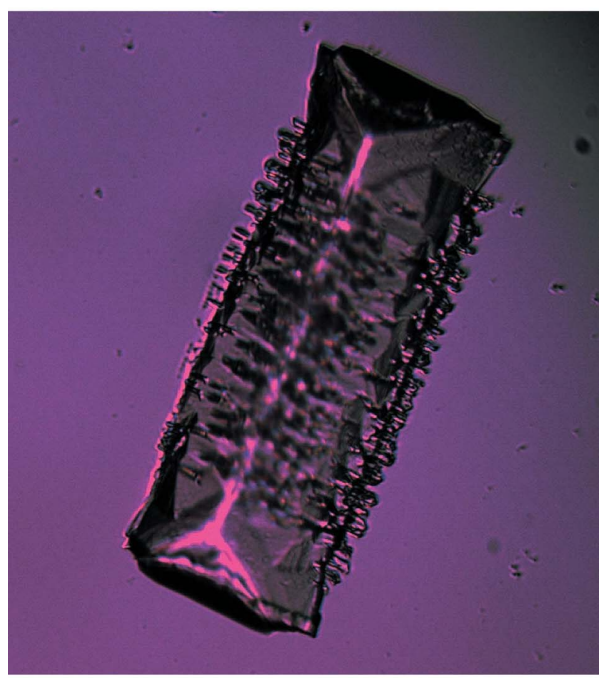

(c)

Figure 3

A cocrystal of Southampton virus protease and the inhibitor MAPI. A freshly grown crystal is shown in $(a)$ and its progressive deterioration over several days is shown in $(b)$ and $(c)$. 
into $10 \mu \mathrm{l}$ well solution using a loop and stirring in four $1 \mu \mathrm{l}$ droplets of glycerol stepwise to give a final glycerol concentration of approximately $30 \%(v / v)$. They were then frozen by plunging them into liquid ethane in a liquid-nitrogen bath. Preliminary data collection using station ID14-1 at the ESRF (Grenoble, France) revealed that the crystals belonged to a hexagonal point group, with unit-cell parameters $a=b=129.5, c=119.7 \AA$. The best crystal only produced diffraction data to medium resolution of rather marginal quality $\left(d_{\min }=2.9 \AA ; R_{\text {merge }}=14.5 \%\right.$ assuming space group $\left.P 6\right)$ and most of the crystals tested only diffracted to between 3 and $4 \AA$ resolution. All attempts at structure analysis by molecular replacement using several search models with this data set were unsuccessful. Ultimately, it was not possible to determine the exact space group of this crystal form or to analyse its structure.

Fortunately, crystals of vastly improved diffraction quality were obtained by forming a complex of the protease with the inhibitor MAPI. To obtain these cocrystals, $\mathrm{NaCl}$ was added to the protein sample to a final concentration of $300 \mathrm{~m} M$, which allowed the protease to be concentrated to $17 \mathrm{mg} \mathrm{ml}^{-1}$ using a $10 \mathrm{kDa}$ cutoff Centricon concentration vessel. To provide suitable conditions to complex the protease with the essentially insoluble inhibitor, it was necessary to include $10 \%$ DMSO in the buffer. An amount of inhibitor giving a threefold molar excess over the protein was dissolved in a volume of DMSO that would, once added to the protein sample, result in the final buffer containing $10 \%$ DMSO. The inhibitor in DMSO was added to the protein sample in ten equal volumes at 10 min intervals. The sample was then passed through a Sephadex G25 Minispin column to rid the complex of any excess unbound inhibitor and DMSO. Incubation of a small volume of protease complex with the chromogenic substrate AcEFQLQ-pNA demonstrated that $100 \%$ inhibition had been achieved. Further confirmation and accurate assessment of MAPI binding was accomplished by mass spectrometry, which revealed a single major peak of molecular weight 20045 corresponding to one molecule of protease covalently linked to one molecule of the inhibitor.

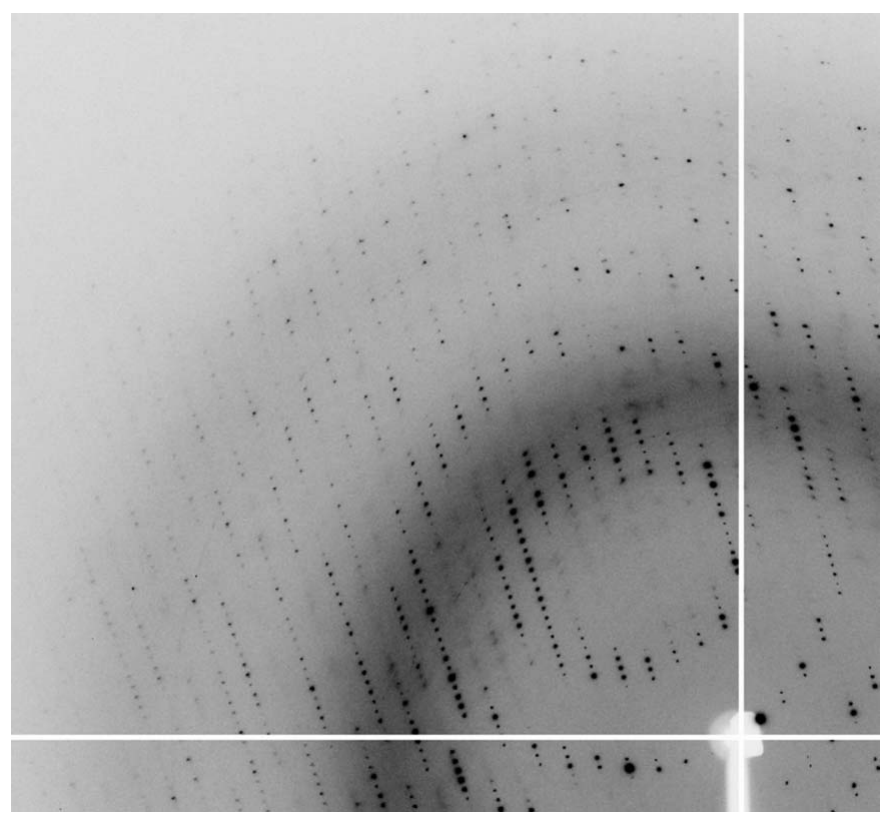

Figure 4

Part of a diffraction image obtained from a cocrystal on beamline ID14-1 at ESRF (Grenoble, France). Diffraction to a resolution of approximately $1.7 \AA$ is visible.
Further screening for crystallization conditions with the enzymeinhibitor complex at a concentration of $15 \mathrm{mg} \mathrm{ml}^{-1}$ yielded large rhomboid crystals in 25\%(w/v) PEG $5000 \mathrm{MME}, 100 \mathrm{mM}$ Tris- $\mathrm{HCl}$ $\mathrm{pH}$ 8.5, $200 \mathrm{~m} M$ lithium sulfate (Jena Bioscience JBScreen Classic 4 condition A1). The cocrystals were extremely clean in appearance and measured between 200 and $400 \mu \mathrm{m}$ in all dimensions (Fig. 3). The cocrystals were cryoprotected in the same manner as the native enzyme. It was found that freezing the crystals within a week of their appearance was crucial to achieving high-quality data. Hence, this was usually performed between 18 and $21 \mathrm{~d}$ of setting up the crystallization experiments. If this time limit was exceeded, the crystals were seen to degrade in an unusual manner, apparently involving a phase change prior to collapse of the crystal (Fig. 3). The proneness of the enzyme to oxidation may be responsible for this deterioration over time.

Data collection at station ID14-1 (ESRF, Grenoble) established that the crystals diffracted to high resolution $(1.7 \AA)$ and gave sharp non-overlapping reflections (Fig. 4), which was a marked improvement on the native crystal data. Using $1^{\circ}$ oscillations, $190^{\circ}$ of data were collected from a single crystal using an ADSC Q210 CCD detector with an exposure time of $6 \mathrm{~s}$ per image and a crystal-todetector distance of $160.1 \mathrm{~mm}$. A low-resolution pass was performed using $1 \mathrm{~s}$ exposures, $3^{\circ}$ oscillations and a crystal-to-detector distance of $391.4 \mathrm{~mm}$ to re-collect the spots that were overloaded in the initial high-resolution pass. Data processing in MOSFLM (Leslie, 2006), SCALA (Evans, 2006) and other programs in the CCP4 suite (Collaborative Computational Project, Number 4, 1994) revealed that the crystals belonged to space group $P 2_{1} 2_{1} 2_{1}$, with unit-cell parameters $a=49.5, b=84.1, c=121.5 \AA$; the data set had an overall $R_{\text {merge }}$ of $5.3 \%$ to $1.7 \AA$ resolution (Table 2). Using the method of Matthews (1968) it was estimated that there were two monomers per asymmetric unit, which corresponds to a solvent content of $61 \%$. Accordingly, a self-rotation function calculated at $2.0 \AA$ resolution with a radius of integration of $25 \AA$ using MOLREP (Vagin \&

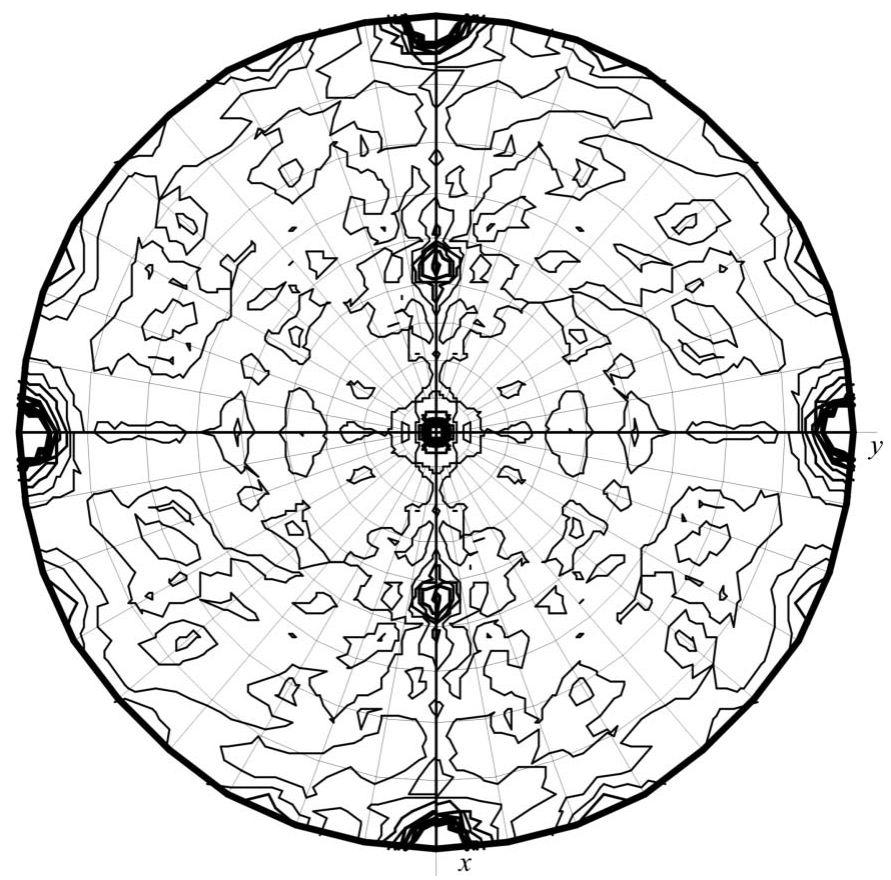

Figure 5

A self-rotation function for the protease-inhibitor complex calculated at $2 \AA$ resolution. The $\chi=180^{\circ}$ section is shown. 
Table 2

Data-collection and processing statistics for the protease-MAPI cocrystal.

Values in parentheses are for the outer resolution shell.

\begin{tabular}{ll}
\hline Beamline & ID14-1, ESRF \\
Wavelength $(\AA)$ & 0.934 \\
Space group & $P 2_{1} 2_{1} 2_{1}$ \\
Unit-cell parameters & \\
$\quad a(\AA)$ & 49.5 \\
$\quad b(\AA)$ & 84.1 \\
$\quad c(\AA)$ & 121.5 \\
Mosaic spread $\left({ }^{\circ}\right)$ & 0.7 \\
Resolution $(\AA)$ & $40.5-1.7(1.8-1.7)$ \\
$R_{\text {merge }}(\%)$ & $5.3(62.3)$ \\
Completeness $(\%)$ & $98.8(92.8)$ \\
Average $I / \sigma(I)$ & $22.4(2.4)$ \\
Multiplicity & $6.7(5.2)$ \\
No. of observed reflections & $376358(38859)$ \\
No. of unique reflections & $55934(7504)$ \\
Wilson plot $B$ factor $\left(\AA^{2}\right)$ & 24.7 \\
Solvent content $(\%)$ & 61.0 \\
No. of molecules per asymmetric unit & 2 \\
\hline
\end{tabular}

$\dagger R_{\text {merge }}=\sum_{h k l} \sum_{i}\left|I_{i}(h k l)-\langle I(h k l)\rangle\right| / \sum_{h k l} \sum_{i} I_{i}(h k l)$, where $\langle I(h k l)\rangle$ is the mean intensity of the scaled observations $I_{i}(h k l)$.

Teplyakov, 2010) showed significant non-axial peaks in the $\chi=180^{\circ}$ section (Fig. 5), suggesting the presence of noncrystallographic twofold symmetry. Structure determination of the selenomethionyl enzyme complexed with the inhibitor in the same crystal form is in progress.

We gratefully acknowledge the School of Biological Sciences, University of Southampton for a studentship award to RJH, Hope (Southampton General Hospital) for a grant to PMSJ and the ESRF (Grenoble, France) for beam time and travel support. The work was also part-supported by a Wellcome Trust grant (reference 086112) to INC and PRL.

\section{References}

Bertolotti-Ciarlet, A., Crawford, S. E., Hutson, A. M. \& Estes, M. K. (2003). J. Virol. 77, 11603-11615.

Clarke, I. N. \& Lambden, P. R. (2005). Virology, edited by B. W. J. Mahy \& V. ter Meulen, pp. 911-931. London: Hodder.

Collaborative Computational Project, Number 4 (1994). Acta Cryst. D50, 760-763.

Dragovich, P. S. et al. (1998a). J. Med. Chem. 41, 2806-2818.

Dragovich, P. S. et al. (1998b). J. Med. Chem. 41, 2819-2834.

Dragovich, P. S. et al. (2003). J. Med. Chem. 46, 4572-4585.

Evans, P. (2006). Acta Cryst. D62, 72-82.

Govardhan, C. P. \& Abeles, R. H. (1996). Arch. Biochem. Biophys. 330, 110-114.

Green, K. Y. (2007). Fields Virology, edited by D. M. Knipe \& P. M. Howley, pp. 949-980. Philadelphia: Kluwer.

Kaspari, A., Schierhorn, A. \& Schutkowski, M. (1996). Int. J. Pept. Protein Res. 48, 486-494.

Kuyumcu-Martinez, M., Belliot, G., Sosnovtsev, S. V., Chang, K. O., Green, K. Y. \& Lloyd, R. E. (2004). J. Virol. 78, 8172-8182.

Lambden, P. R., Caul, E. O., Ashley, C. R. \& Clarke, I. N. (1993). Science, 259, 516-519.

Lambden, P. R., Liu, B. L. \& Clarke, I. N. (1995). Virus Genes, 10, 149-152.

Leslie, A. G. W. (2006). Acta Cryst. D62, 48-57.

Liu, B. L., Clarke, I. N. \& Lambden, P. R. (1996). J. Virol. 70, 2605-2610.

Liu, B. L., Viljoen, G. J., Clarke, I. N. \& Lambden, P. R. (1999). J. Gen. Virol. 80, 291-296.

Matthews, B. W. (1968). J. Mol. Biol. 33, 491-497.

Matthews, D. A., Smith, W. W., Ferre, R. A., Condon, B., Budahazi, G., Sisson, W., Villafranca, J. E., Janson, C. A., McElroy, H. E., Gribskov, C. L. \& Worland, S. (1994). Cell, 77, 761-771.

Merrifield, R. B. (2007). J. Am. Chem. Soc. 85, 2149-2154.

Nakamura, K., Someya, Y., Kumasaka, T., Ueno, G., Yamamoto, M., Sato, T., Takeda, N., Miyamura, T. \& Tanaka, N. (2005). J. Virol. 79, 13685-13693.

Rink, H. (1987). Tetrahedron Lett. 28, 3787-3790.

Schechter, I. \& Berger, A. (1967). Biochem. Biophys. Res. Commun. 27, $157-162$.

Vagin, A. \& Teplyakov, A. (2010). Acta Cryst. D66, 22-25.

Whitmore, A. J., Daniel, R. M. \& Petach, H. H. (1995). Tetrahedron Lett. 36, 475-476.

Zeitler, C. E., Estes, M. K. \& Prasad, B. V. V. (2006). J. Virol. 80, 5050-5058. 